\title{
A crítica cinematográfica como campo de disputa política no Uruguai: a repercussão do documentário Elecciones (Mario Handler / Ugo Ulive, 1967).
}

\author{
Film criticism as a field of political dispute in Uruguay: the \\ repercussion of the documentary Elecciones (Mario Handler / Ugo \\ Ulive, 1967).
}

Mariana Martins Villaça'

RESUMO

Analisamos o contexto de produção e a repercussão do documentário uruguaio Elecciones (Mario Handler/ Hugo Ulive, 1967) nas páginas do semanário Marcha. Esse periódico exerceu importante papel de agente de política cultural, consolidando um circuito cultural de esquerda no Uruguai, em um contexto de franco acirramento do autoritarismo. Demonstramos que a polêmica em torno do documentário desencadeou uma série de debates e críticas na imprensa que extrapolaram o universo cinematográfico, revelando, também, o alcance da atuação da direção de Marcha na cena cultural montevideana. $O$ filme se mostra, ainda, como documento histórico privilegiado para a compreensão dos dilemas políticos daquele momento, e do impasse vivido pela própria direção do jornal, entre a defesa incondicional da democracia e a descrença nas vias institucionais como possibilidade real de saída da crise política e econômica vigente no país.

Palavras-chave: Semanário Marcha. Documentário uruguaio. Crítica cinematográfica. Política cultural. Autoritarismo.

\section{ABSTRACT}

We analyze the production and the impact of the Uruguayan documentary Eleccione (Mario Handler/ Hugo Ulive, 1967) at the weekly newspaper Marcha. This journal played an important role as agent of leftist cultural policy, in a context of increasing authoritarianism. We demonstrated that the controversy

\footnotetext{
* Esse artigo é fruto de uma investigação em andamento, que conta com Auxílio Regular à Pesquisa FAPESP, e tem como título As edições Marcha e a constituição de um circuito cultural de resistência política frente o acirramento do autoritarismo no Uruguai (1967-1974).

1Docente do Departamento de História e do Programa de Pós Graduação em História da Universidade Federal de São Paulo (Unifesp). Coordenadora do Laboratório de Pesquisas de História das Américas (LAPHA) na mesma instituição.
} 
on the documentary triggered a series of debates and criticism in the press that extrapolated the cinema universe, and shifting the crucial role of the Marcha in the cultural scene. The film Elecciones is an important historical source for understanding the political dilemmas and debates in that moment. He revealed the impasse experienced by the staff of the newspaper, from the unconditional defense of democracy and the lack of trust in institutional channels as real possibility to overcome the political crisis in the Uruguay.

Keyword: Weekly Marcha. Uruguayan documentary. Film criticism. Cultural policy. Authoritarianism.

\section{Introdução}

Apresentamos, nesse trabalho, um recorte da pesquisa que desenvolvemos atualmente e que tem como objeto o semanário uruguaio Marcha e sua importância na cena política e cultural desse país, entre 1967 e 1974. Nesse período ocorreu notável acirramento do autoritarismo que culminou no golpe de 27 de junho de 1973 e na instituição de um regime civil-militar marcado por forte repressão política $^{2}$, que implicou, entre outras consequências, em ações de perseguição, censura e no fechamento desse e de outros periódicos uruguaios.

Interessa-nos, nesse artigo, analisar a repercussão do documentário Elecciones (Mario Handler/ Ugo Ulive, 1967) como forma de mostrar a dimensão política que as opiniões e a discussão sobre o cinema nacional adquiriram nesse momento da história uruguaia, no qual as paixões políticas se acirravam, em parte revestidas do fervor revolucionário inspirado pela Revolução Cubana, pelo movimento estudantil emergente no país, pelas notícias que circulavam sobre o regime militar brasileiro e pela clara sinalização, por parte do governo uruguaio, de que não mais toleraria formas contundentes de oposição política. A polêmica em torno do filme Elecciones deu margem a um candente debate sobre a conjuntura política nacional e a avaliação da democracia no país. Além disso, tendo em vista as ações que tal polêmica desencadearam (as quais apresentaremos a seguir), nos interessa chamar a atenção para o protagonismo da direção de Marcha como promotora de política cultural, interferindo diretamente no espaço público por meio da defesa da autonomia universitária e das críticas lançadas a um importante organismo estatal no âmbito da cultura, e, sobretudo, por meio da criação de espaços e eventos que passam a conformar, na cena montevideana, um expressivo circuito cultural de esquerda.

2 Há importantes pesquisas que mostram a escalada autoritária que antecede o golpe civil-militar de 1973, evidenciando que eclosão da luta armada e o auge da repressão à mesma antecedem, nesse país, a institucionalização da ditadura. Ver: Padrós (2005), Markarian(2012), Rey Tristán(2006). Especificamente sobreo período ditatorial, ver, para o entendimento do processo histórico: Caetano e Rilla. Para um balanço da historiografia produzida sobre o tema, ver: Marchesi et al. (2004). 


\section{Breve apresentação do semanário Marcha}

Marcha foi uma publicação semanal de grande prestígio e circulação no país, cuja ênfase recaía sobre temas políticos do momento e sobre o contexto nacional, sem abdicar, entretanto, de um generoso espaço à crítica literária e às artes em geral ${ }^{3}$. Pode ser considerada uma publicação longeva para os padrões latino-americanos, visto que circulou entre 1939 e 1974. Sua direção e a ampla equipe de colaboradores desse periódico tiveram atuação muito significativa na resistência política e cultural no final dos anos 1960 até o primeiro ano da ditadura uruguaia, quando a publicação foi encerrada e a maioria de seus integrantes partiu para o exílio ${ }^{4}$. Ainda sim, mesmo no exterior, parte da equipe conseguiu viabilizar uma forma de sobrevivência no exterior por meio da continuidade da edição de uma publicação mensal criada em 1967: os Cuadernos de Marcha, sobre os quais trataremos mais adiante. O semanário Marcha, nossa fonte e objeto de pesquisa, possuía cerca de 30 páginas, pouca publicidade, poucas ilustrações (ainda que não passassem desapercebidas por sua qualidade, mesmo ocupando espaços reduzidos nas páginas, criativamente preenchidos por gravuras, desenhos e caricaturas) e muitos artigos, vários deles longos e densos, que podiam se estender por mais de um número e pressupunham um leitor bem formado, familiarizado com ensaios políticos, críticas que não abriam mão de vocabulário específico, expressões em língua estrangeira e referências a trabalhos acadêmicos ${ }^{5}$.

Durante décadas, Marcha teve como diretor o intelectual e político Carlos Quijano que reuniu, principalmente nos anos 1960, uma equipe de colaboradores surpreendente no campo da política e da cultura: dela participaram de forma assídua os principais nomes da intelectualidade uruguaia conhecida como "la generación crítica" (ALDRIGUI, 2001, p. 108; DE ARMAS; GARCE, 1997, p. 59). Entre esses nomes encontravam-se Ángel Rama, Mario Benedetti, Eduardo Galeano, Carlos Real de Azúa, Manuel Martinez Carril, Hugo Alfaro, bem como figuras referenciais das esquerdas no mundo todo, muitos dos quais portadores da bandeira do latinoamericanismo, tão em voga naquele momento ${ }^{6}$. Referimo-nos a nomes como Gabriel García Márquez, Mario Vargas Llosa, Julio Cortázar, Che Guevara, Alejo Carpentier, Jean Paul Sartre, Regis Debray, entre outros.

3Marcha tinha cerca de um terço da publicação voltado à economia e à política (principalmente nacionais), mas havia equipes específicas responsáveis por seções fixas integralmente dedicadas à cultura: "Espectáculos", "Plásticas", "Literárias". Sobre Marcha, há obras testemunhais que dão grande destaque à crítica literária e política, como Rocca (1992) e Alfaro (1984). Há tambémimportantes estudos acadêmicos que focam diferentes aspectos do semanário e seu impacto dentro e fora do Uruguai: Machín e Moraña (2003), Reis (2012).

4 Carlos Quijano, o fundador e diretor, durante décadas, de Marcha, foi obrigado a exilar-se no México em 1975. Julio Castro, chefe de Redação que havia participado da criação desse periódico com Quijano, em 1939, tornou-se um "desaparecido" da ditadura uruguaia em 1977.

5 O semanário Marcha foi digitalizado integralmente e encontra-se disponível para consulta em $<$ http://biblioteca.periodicas.edu.uy>.

6 A historiadora Maria Ligia Prado, sob a perspectiva brasileira, aborda o cerne desse latinoamericanismo, o qual denomina "utopia latino-americana": (PRADO, 2011). 
Marcha circulou além das fronteiras uruguaias, abarcando um público intelectualizado e de esquerda nos anos 1960 e 70, e conseguiu se manter como uma referência de imprensa combativa ao subsistir, ainda que sob condições precárias, após seu encerramento no Uruguai. Isso foi possível uma vez que, além do semanário, a direção de Marcha passara a editar, em 1967, os já mencionados Cuadernos de Marcha (dossiês monotemáticos, mensais) cujo formato, bem mais versátil e menos regular que o do semanário, facilitou sua continuidade. Eles foram editados no México, durante o exílio, e após o regresso da equipe ao Uruguai, foi produzido novamente no país até 2001. ${ }^{7}$ Após o fim da ditadura, boa parte da equipe de Marcha criou, em 1985, o periódico Brecha, existente até hoje no Uruguai ${ }^{8}$.

\section{Crítica de cinema em Marcha}

Dentre as páginas do semanário Marcha dedicadas à cultura nas suas mais diversas expressões (artes plásticas, teatro, literatura, poesia, cinema, música erudita, música popular), podemos encontrar em seções como 'Montevideo en las carteleras' ou "Espectáculos", densos artigos de crítica de cinema. Antes dos anos 1960 estes eram predominantemente voltados à produção europeia e norte-americana, e, em geral, assinadas por nomes já respeitados no campo artístico e cinematográfico nacional, como Manuel Martínez Carril, Hugo Alfaro e José Wainer. A pretexto das estreias no país - sempre abundantes, considerando o farto número de salas, cineclubes que caracterizavam a notável cinefilia uruguaia (SARATSOLA, 2005); - ou da realização de algum festival internacional, Marcha publicava resenhas de fôlego, destinadas a um público cinéfilo, bem informado sobre as últimas tendências das produções norte-americanas, europeias, e até conhecedor de termos técnicos do fazer cinematográfico.

Mário Handler, cineasta e, nos anos 1960, também colaborador de Marcha, satiriza essa vocação para a crítica, historicamente predominante no país: "[...] en un país donde había muchas cosas que no se hacían, lo único que funcionaba era una hipercrítica brutal. Los reyes, los que mandaban más, eran los críticos" (CONCARI, 2012, p. 39). Além da ausência de uma expressiva produção nacional, que deve ser compreendida em função de limitações de mercado, da falta de tradição de realizadores, e das dificuldades econômicas do momento, devemos ponderar que tal produção vinha ao encontro de uma cinefilia sofisticada e

7 Em 1967 criou-se tambéma coleção chamada Biblioteca de Marcha, composta por livros editados nos Talleres Gráficos do periódico, mas que não sobreviveu a 1974. Sobre os Cuadernos, ver: Peirano Basso (2001).

8 O semanário Brecha teve seu primeiro número em 11 de outubro de 1985. Em sua equipe, figuravam os seguin tes colaboradores de Marcha: Hugo Alfaro, Mario Benedetti, Oscar Bruschera, Guillermo Chifflet, Eduardo Galeano, Ernesto González Bermejo, Carlos María Gutiérrez, Carlos Núñez, Héctor Rodríguez, José Wainer, Guillermo Waksman, Coriún Aharonian, Gabriel Peluffo. Disponível em: <http://brecha.comuy/historia $>$. 
disseminada. Havia, portanto, demanda pelo consumo de crítica dado o intenso consumo de cinema no país e o bom nível de formação intelectual da classe média, proporcionado, em grande medida, pela educação pública e laica de qualidade, que até os anos 1950, contribuíra para que o país ostentasse o rótulo de "Suíça da América Latina". De todo modo, na fala de Handler percebemos sua insatisfação com o parco saldo da produção cinematográfica nacional, realidade com a qual esse e outros jovens cineastas se defrontavam nos anos 1960.

No final da década de 1950, o espaço, no periódico, destinado a resenhar a produção latino-americana, sobretudo após o Primer Congreso Latinoamericano de Cineastas Independientes del Sodre (Servicio Oficial de Difusión, Radiotelevisión y Espectáculos) em 1958, se alargou substancialmente com o despontar das discussões sobre o nuevo cine latinoamericano ${ }^{9}$. Esse interesse veio acompanhado de várias - e cada vez mais convictas iniciativas institucionais da direção do jornal para a promoção desse cinema e o estímulo à produção nacional. Essa disposição em apoiar o cinema uruguaio e, de modo geral, o bom cinema independente que vinha sendo produzido na América Latina, culminou no crescente empenho do periódico na realização dos Festivales de Cine de Marcha. Estes, no final dos anos 1960, se contrapunham ao estilo de festivais de caráter mais "mercadológico" e afinados com interesses de distribuidoras internacionais, como o Festival Internacional de Cine de Punta del Leste e concorriam abertamente com o popularmente chamado Festival del Sodre. Este último, auspiciado pelo Sodre, um organismo estatal que era importante braço do Ministério da Cultura, havia sido bastante ousado em suas primeiras edições, mas passara a atender de forma mais explícita as necessidades e os interesses do governo e do mercado, ao longo da década seguinte.

Na segunda metade dos anos 1960 encontramos nos artigos de Marcha um crescente descontentamento da direção e de sua equipe de cinema com os critérios de seleção do Festival del Sodre, bem como com a falta de compromisso desse organismo na promoção do cinema nacional (uma vez que a isso deveria se prestar, como órgão estatal) e na difusão da produção latino-americana, em favor da preferência a produtos "hollywoodianos" ou mais palatáveis ao gosto comercial. Tal insatisfação resultou na preparação cuidadosa da $10^{\mathrm{a}}$ edição do Festival de Marcha como uma resposta à política de seleção e à dinâmica institucional vigentes nos outros festivais tradicionais do país. Assim, em 1967, Marcha organiza seu festival inteiramente dedicado a filmes "políticos". Verificamos que, dentre os diversos fatores que motivam o empenho nessa realização, esteve a polêmica surgida em torno de uma produção nacional recente, o documentário Elecciones, que aqui procuraremos apresentar. Vale destacar que o ano de 1967 pode ser visto como um marco, um divisor de águas na atuação do periódico junto ao cinema nacional. Isso fica patente não apenas nas ações desse ano como em sua continuidade nos anos seguintes: em 1968, Marcha cria um

9 Para a compreensão da multiplicidade de expressões que integraram o complexo nuevo cine latinaomericano e os princípios que nortearama defesa, durante décadas, desse movimento supostamente continental ver: Del Valle Dávila (2014), Núñez (2009). 
departamento específico para o cinema junto a sua equipe de redação; funda, pouco depois, um cine-clube do próprio periódico (Cine Club de Marcha, em 1969) e, em seguida, apoia a criação de uma Cinemateca independente, derivada desse mesmo cine-clube (a Cinemateca del Tercer Mundo, fundada também em 1969), com o intuito de constituir um acervo internacional de filmes "políticos", produzir curtas documentais e editar uma revista especializada no tema, a Cine del Tercer Mundo. ${ }^{10}$

\section{Marcha como agente de política cultural}

Além da importância como espaço de expressão de opiniões políticas e de avaliações estéticas refinadas, conforme já frisamos, Marcha era também responsável pela promoção de múltiplos eventos políticos e culturais na capital uruguaia, prática que vai se intensificando ao longo nos anos 1960. Debates públicos e mesas redondas sobre a situação dos equipamentos culturais, sobre os Salões de Artes Plásticas, sobre a programação da TV estatal, a cena teatral contemporânea, a viabilidade dos projetos divulgados pelo Ministério da Cultura, entre outras formas de avaliação e inserção direta na cena cultural tinham visibilidade e divulgação constante nas páginas do semanário. Além disso, Marcha organizava minuciosas premiações anuais em todos os campos artísticos (algo como "os melhores do ano" de cada área), alocava sua sede para a realização de encontros, vendas de livros e ingressos, difundia todo tipo de seminário, eventos e mobilizações conclamadas por organizações políticas e associações. Como se vê, não nos parece exagero considerar a direção de Marcha como agente de política cultural de forte atuação no país, nesse período.

Dentre as muitas ações que marcaram a política cultural do semanário Marcha, visíveis em suas páginas, entendemos que o cinema latino-americano, nele incluída a produção nacional, foi especialmente visado. Junto com a literatura, o cinema foi alvo de muitas iniciativas e especial atenção nas seções do periódico, que além de abrigarem resenhas de produções recentes, expressaram posições sobre o imperialismo cultural (tanto no âmbito dos países capitalistas influenciados pelos EUA como no bloco socialista), as dificuldades de distribuição do cinema independente, o perfil das publicações dos cine-clubes uruguaios, as necessidades de fomento e incentivo à produção nacional, os bastidores de festivais importantes, dentre outros temas que sempre permearam o universo cinematográfico, mas que ganham maior importância dentro de Marcha na década de sessenta.

10 A respeito da história dessa peculiar cinemateca e sua revista, que se restringiu a apenas dois números, ver: Villaça (2012). 


\section{O filme Elecciones e seu contexto de produção}

Sob um cenário de efervescência mundial do cinema de denúncia social e apelo à revolução, com grande projeção do documentarismo, a crítica cinematográfica uruguaia protagonizou um conflito político acirrado em torno do filme Elecciones. Esse médiametragem de 36 minutos havia sido realizado em 1966 pela dupla Mario Handler e Ugo Ulive, com apoio do Instituto de Cinematografia de la Universidad de la República (ICUR) e lançado no final de $1967^{11}$.

Mário Handler, um dos realizadores, vinha sendo colaborador eventual de Marcha desde seu regresso ao país, em 1964, após ter estado por quase um ano em Praga, onde realizou cursos de cinema, assim como na Alemanha Oriental e na Holanda (Utrecht), anteriormente. No circuito "socialista" de festivais e escolas voltadas especialmente ao cinema documental, Handler era considerado um cineasta promissor, talentoso e havia sido escolhido para ser jurado do prêmio "Terceiro Mundo" do Festival de Karlovy Vary (cidade da atual República Tcheca), importante evento no campo do documentarismo. No Uruguai, o reconhecimento profissional era recente e viera com a repercussão de seu documentário Carlos, el cine-retrato de un caminante (1965), alvo de muitos elogios em Marcha ${ }^{12}$. Esse documentário de 31 minutos havia sido realizado, tal como ocorrerá com Elecciones, mediante apoio do ICUR (Instituto de Cinematografia de la Universidad de la República), onde Handler trabalhava como "cineísta docente"13. Em Carlos, Handler registrara o cotidiano de um mendigo, a quem acompanhou pelas ruas de Montevidéu por cerca de 10 meses, valorizando o discurso desse personagem, cujas falas guiam o espectador por todo o documentário. Estas se alternam entre comentários lúcidos e conscientes sobre sua condição e a realidade do país, e momentos que parecem delirantes, porém permeados de lirismo. Nesse documentário, Handler também foca a solidariedade que existe entre os moradores de rua, os contrastes entre a Montevidéu moderna e os locais da cidade marcados pela feiura, pobreza e abandono. Esse olhar muito interessado em registrar uruguaios não brancos ou bemnascidos, que viviam à margem das benesses do consumo e expunham o lado subdesenvolvido do país, reapareceria, revestido de contornos políticos, em Elecciones.

Seu parceiro nessa realização, Ugo Ulive, vinha de uma longa carreira teatral e gozava de uma reputação consagrada como ator e diretor do premiado grupo teatral El Galpón, fundado em 1950 (ULIVE, 2007, p. 45). Já possuía, também, uma bem sucedida incursão pelo cinema, tendo realizado o curta-metragem Como el Uruguay no hay (1960), que trazia um

11 Ficha Técnica ver: (ELLECIONES, 1967).

12 O jornal publicou notícias e elogios sobre a repercussão do filme no Festival de Vinã del Mar, no Chile: Wainer (1967a). 13 É esse o termo - cineísta docente grado 3 - que designava a função de Handler. O sucesso de Carlos, cine-retrato de un caminante (1965) facilitou a Handler angariar financiamento junto ao Consejo Directivo Central da Universidade. (CONCARI, 2012, p. 39-46). 
debochado tom de crítica à cena política uruguaia - tom semelhante, ainda que menos sutil, ao de Elecciones. O título desse curta de 1960, muito irônico, se servia de um lema nacionalista para refutar a imagem de "Suíça da América Latina" numa postura que muito tinha em comum com a da "generación critica", e que, por isso mesmo, contou com imediata aprovação em resenhas publicadas em Marcha e em outros jornais ${ }^{14}$.

As filmagens de Elecciones duraram seis meses, de maio a novembro de 1966, e o filme foi lançado no ano seguinte. A parceria entre os dois realizadores, que constituíam "a equipe", funcionou do seguinte modo: Ugo Ulive fazia a produção, os contatos prévios, captava o som e Handler era responsável pela filmagem, pela parte técnica e pela administração dos recursos.

O documentário registrava, em tom de reportagem televisiva e com pitadas de crítica política, as campanhas eleitorais de dois candidatos, em 1966: Amanda Huerta de Font, dama elegante de Montevidéu, candidata a deputada pelo Partido Colorado, e Salviniano Pérez, conhecido como 'Nano', político vinculado ao meio rural ${ }^{15}$ com evidentes traços de caudilho, candidato a "intendente" (cargo similar a de prefeito, no Brasil) pelo Partido Nacional em Cerro Largo. Marcha sintetiza com alguma sutileza o caráter de denúncia desse documentário:

El filme presenta dos políticos: de sus paralelismos, ademanes comunes y contrastes más o menos reductibles, el film extrae una imagen precisa, irreprochable de nuestras costumbres [...]. Ni la irresistible simpatia del personaje [Nano Perez] puntualmente anotada por la cámara, esconde la ominosa realidade de la que se nutre [...].(WAINER, 1967e, p. 25).

O média-metragem, sem ocultar a presença das câmeras e contando com a cumplicidade dos candidatos, cobria diversas situações das respectivas campanhas políticas, culminando no momento das eleições de 1966. Essas eleições, as últimas antes da tumultuada década de 1970, tiveram destacada importância na história política uruguaia por virem acompanhadas de uma reforma constitucional (sobre a qual se realizou, na mesma ocasião, um plebiscito

14 Esse documentário curta-metragem, feito ao modo de colagem de fragmentos que denunciavama realidade uruguaia, abordando problemas de diversas ordens em tom sarcástico (como a derrocada econômica do país, a corrupção na política, as desavenças entre socialistas e comunistas, etc) foi barrado pela direção do Sodre em um concurso promovido por esse organismo no qual o filme fora inscrito na categoria "cine turístico". Em sua defesa, no entanto, Mario Benedetti publicou uma resenha em Marcha intitulada "Vino nuevo en Sodre viejo" e Gerardo Gatti, um artigo celebrativo intitulado "Los diez minutos que conmovieron al Sodre", no jor nal Lucha Libertaria. (ULIVE, 2007, p. 144-145).

15 Atuante na cidade de Melo, capital do departamento de Cerro Largo e situadana divisa do Uruguai com o estado do Rio Grande do Sul, Brasil. 
que a aprovou). Por meio dessa reforma ocorreu o fortalecimento do poder do Presidente (Executivo), em detrimento do poder do parlamento, uma vez que o país deixava de ser efetivamente governado pelo Conselho Nacional, como era até então. Essa medida foi encampada com o argumento de que tal mudança propiciaria maior eficácia na implementação de medidas econômicas emergenciais para tirar o Uruguai da crise em que vinha mergulhado desde meados dos anos cinquenta ${ }^{16}$. Nessas eleições de 1966, a disputa política continuava polarizada, seguindo a tradição uruguaia, entre um candidato "blanco" (como eram conhecidos os candidatos do Partido Na cional), Alberto Galllinal, e seu oponente colorado, Oscar Gestido, que vence as eleições.

A despeito dessa polarização, a chamada Ley de lemas (lei de legendas) tornara possível o surgimento de nove candidatos a presidência, vários deles entrevistados para o documentário (ainda que nem todas as entrevistas tivessem sido aproveitadas) ${ }^{17}$. Vemos, assim, que, além da crise econômica, havia também uma crise política instaurada, que colocava em cheque o histórico controle do país pelos dois partidos tradicionais que, nesse momento, passavam por processos internos de divisionismos e reagrupamentos, mas que ainda possuíam considerável afluência em todas as esferas de poder. Os limites da reforma constitucional que acompanharam as eleições de 1966 são apontados por especialistas em ciência política: "con las modificaciones constitucionales se lograba la ilusión de haber realizado cambios, aunque en realidad no se hubiese operado ninguna transformación de fondo". (NAHUM et al., 1993 apud REY TRISTÁN, 2006, p. 28).

O Uruguai, nesse momento em que Elecciones é produzido, cabe esclarecer, ainda não enfrentava o autoritarismo que seria institucionalizado dois meses depois da estreia do filme: em outubro de 1967, o presidente Gestido decreta as Medidas Prontas de Seguridad, junto com medidas econômicas de austeridade (como o congelamento de preços e salários). Essa guinada autoritária se completa após a morte de Gestido e a posse de seu vice, Pacheco Areco, que em dezembro dá inicio a um período conhecido como "Pachecato" e que se estende até fevereiro de 1972. Marcha, cuja direção se mostra simpática à formação de uma frente única de oposição a Pacheco, a partir de 1970 apoia incisivamente a fundação da Frente Ampla, coalizão de esquerda constituída no país como alternativa aos partidos tradicionais (Nacional e Colorado) em torno da candidatura de Líber Seregni para disputar as eleições presidenciais ${ }^{18}$. Esse candidato, entretanto, não sairia vitorioso nas eleições de 1971, registrando-se mais um fracasso da "via legal".

16 A reforma constitucional em questão, denominada "Reforma Naranja", foi vitoriosa após concorrer com distintas propostas de reformas, em 1966, e obter os votos de 75\% do eleitorado. Postulava o fim do Executivo Colegiado e a retomada do Executivo unipersonal. (FERREIRA, 2011, p. 178). Ver também: (CHASQUETTI, 2004, p. 64-93).

17 Concari (2012, p. 56) assim lista os entrevistados e suas filiações políticas: Zelmar Michelini, Amilcar Vasconcellos, Jorge Batlle (colorados), Alberto Gallinal e Alberto “Titito" Heber (partido nacional), Alba Roballo (colorado setor batllista), Martín Echegoyen (nacional setor herrerista).

18 Esse apoio se faz patente com a publicação de uma declaração de Marcha assinada por diversas personalidades. "Declaración: por un frente amplio". Marcha, Montevidéu, n. 1514, 9 out. 1970, p. 7. Sobre a fundação da Frente Ampla e a participação das diferentes organizações, (FERREIRA, 2011). 


\section{Enredo e proposta de Elecciones}

As captações expunham, alternando o foco entre dois candidatos, a simpatia peculiar de cada um desses carismáticos políticos: Amanda exercendo um apelo "maternal", personificando o papel de protetora dos pobres (performance que parece aludir à figura de Eva Perón), e Nano colocando-se como "amigo", compadre de seus eleitores. A trilha sonora é um ponto forte da obra, uma vez que explora gêneros musicais típicos de cada localidade onde estão os redutos eleitorais, bem como os jingles de campanha dos candidatos (há, por exemplo, uma sequência em que Amanda canta seu próprio jingle, com franca emoção, atitude que desperta no espectador sensações ambíguas, visto que a cena é patética e comovente ao mesmo tempo). O documentário deixa aflorar, sob uma chave irônica, o discurso demagógico de ambos, sem que os candidatos sejam confrontados ou inquiridos abertamente. $O$ foco também se dirige aos eleitores simpatizantes de um e de outro (em geral, pessoas humildes) e salienta seus comportamentos ingênuos, suas atitudes clientelistas, certa cultura política afeita a oportunismos, à troca de favores. A obra parece inspirada pelo documentário norte-americano Primary (1960), de Robert Drew, sobre as campanhas políticas de Hubert H. Humphrey e John F. Kennedy, que havia sido realizado no formato de cinema direto, para a televisão. Uma das intenções de Elecciones é mostrar como os dois partidos tradicionalmente rivais no Uruguai, o Colorado e o Nacional, possuíam muitas semelhanças em termos de discurso e prática política, lançando mão de estratégias fáceis (e eticamente questionáveis) para angariar apoio popular, como a compra de votos, ainda que as campanhas presidenciais fossem um tanto embasadas em discursos pela moralidade, honra e integridade (REY TRISTÁN, 2006, p. 29). Ao tratar das inspirações do filme, Handler não menciona influências decisivas, mas afirma ter lido (e ao fim desprezado) um artigo do sociólogo Aldo Solari publicado no jornal La Gaceta sobre as eleições realizadas em novembro de 1966 (CONCARI, 2012, p. 49) ${ }^{19}$. Mesmo negando a importância dos balanços acadêmicos de época, acreditamos que o simples fato de Handler lembrar desse artigo ao contar a história do documentário já denota que pode ter sido uma referência não tão desprezada como afirma.

É preciso destacar que outro ponto forte do documentário - e que coincide com o momento mais polissêmico - é seu final, concebido por Ugo Ulive e que se mostra ideologicamente ambíguo. Na última sequência vemos um caminhão velho, trafegando por ruas de terra de um bairro pobre. Seu motorista, pelo alto-falante, convoca os moradores do bairro para uma assembleia, realizada com o propósito de "mudar a situação atual". Esse lugar não é identificado para o espectador: tanto pode localizar-se na periferia de

19É provável que o artigo em questão seja “Elecciones 1966. Cambio ... sin cambiar”, publicado naquele ano em: Gaceta de la Universidad, Montevideo, v. 8, n. 40, p. 5-8, 1966. O mesmo texto foi republicado no final dos anos 1980 em: (SOLARI, 1988). Agradeço o parecerista da revista Antítesis que avaliou o presente artigo por esta valiosa informação. 
Montevidéu como em uma cidadezinha do interior - hoje sabemos, por meio de uma publicação recente de Handler, que a cena foi filmada no "curral eleitoral" de Nano, em cima de um caminhão que era usado em sua própria campanha. (CONCARI, 2012, p. 54) O espectador também não sabe qual partido ou organização faz a convocação, e nem se este poderia ser "de esquerda" ou "de direita", blanco, colorado ou de alguma pequena legenda. No entanto há, no discurso proferido pelo motorista, um apelo comunitário que inclina a plateia a supor se tratar de uma associação de bairro ou partido de oposição buscando se organizar, ou seja, uma possível terceira via. De toda forma, o que a câmera mostra são meninos correndo atrás e junto do caminhão, no qual tentam subir. Finalizando a sequência, em close, temos o olhar de um deles encarando o espectador, com ar interrogativo e sob total silêncio (o som ambiente que se ouvia até então é deliberadamente interrompido).

A voz fílmica, com esse final, parece jogar para o espectador a responsabilidade por uma mudança. Por meio do olhar direto do menino, o filme parece interrogar o público (presumidamente uruguaio, a quem o filme se dirige), a respeito de sua responsabilidade diante da cultura política vigente ${ }^{20}$. Esse momento seria, portanto, o de um apelo revolucionário, um convite à ação. Uma segunda leitura (dentre muitas possíveis) poderia atribuir a essa sequência o "diagnóstico", em tom mais pessimista, de que a continuidade das práticas políticas se impõem cotidianamente da do o desamparo das comunidades que delas são coniventes, não importando muito que organização esteja atuando. O olhar motivaria, nesse sentido, a constatação da impotência.

A riqueza do documentário, a nosso ver, está justamente nesse final "aberto", de clima interrogativo, em que várias possibilidades interpretativas se descortinam, após feita a denúncia. Vale ressaltar que o filme não acusa simplesmente os políticos: mostra sutilezas de seu comportamento populista e de um "sistema" pretensamente democrático cuja engrenagem funciona pois conta com a adesão popular, com a cumplicidade dos uruguaios.

\section{A polêmica sobre um filme não visto]}

Antes mesmo de o filme ser lançado, em fevereiro de 1967, apareceram críticas em diversos jornais (El Diário, La Manãna, El País, El Plata), fazendo campanha contra o filme. $\mathrm{O}$

20 A força do olhar decrianças ou pessoas humildes fitando a câmera é um recurso que podemos encontrar em filmes neo-realistas italianos e em muitos documentários de denúncia social que já haviam circulado pela América Latina, como Tiré Dié (Fernando Birri, 1959), Maioria Absoluta (Leon Hirszman, 1964) entre outros. Isadora Remund ini analisou esse recurso presente em Maioria Absoluta, dialogando com a ideia, exposta na obra de Jean Claude Bernadet, Cineastas e Imagens do Povo (São Paulo: Companhia das letras, 2003) de que esses olhares atuam como "vocativos visuais" e tem, como um de seus efeitos, instigar o sentimento de culpa no espectador. (REMUNDINI, 2015, p. 67). 
leitor de Marcha é informado da existência de todas essas críticas no artigo em que um dos diretores, Ugo Ulive defende o filme das "falácias" que identifica nas resenhas e artigos publicados sobre a obra ${ }^{21}$. Surpreendentemente, a maioria dos redatores dessas críticas revelam ou aparentam não ter visto o filme, que foi exibido comercialmente apenas meses depois, em 4 de agosto de 1967, após ter alguns trechos exibidos no $X$ Festival de Cine de Marcha, em 24 de junho de $1967^{22}$. A polêmica que aflora nas páginas da imprensa, portanto, tem como pivô um filme ainda não exibido.

As resenhas sobre o filme, provavelmente baseadas em sinopses ou em comentários de críticos que igualmente não haviam visto o filme, como Manuel Martinez Carril ${ }^{23}$, acusavam a obra de ridicularizar figuras públicas, além de construir uma imagem da política uruguaia como "imoral, baixa e corrupta" (ULIVE, 1967, p. 11). Martinez Carril afirmava que intencionalmente ou não, o documentário esculhambava a democracia uruguaia, satirizando os candidatos e, com isso, dando motivos "de bandeja" para os conservadores atacarem o regime atual e a incapacidade do povo uruguaio de escolher seus representantes, bem como a universidade pública que patrocinara tal "escândalo".

Marcha informa que outra crítica sugeria que o documentário expressava conteúdo subversivo condizente com o histórico de seus realizadores, uma vez que Ugo Ulive acabara de chegar de Cuba, onde estivera por cinco anos, e Mario Handler, da Tchecoeslováquia, tendo já no histórico um documentário sobre um mendigo (Carlos), que condenava a sociedade uruguaia, a modernidade excludente de Montevidéu e a economia decadente do país. No periódico La Plata, um artigo sobre o filme alertava para o fato de que o conteúdo subversivo de Elecciones estava sendo apoiado pela Universidade da República, que atualmente encontrava-se "sovietizada" (ULIVE, 1967, p. 11). Já o Editorial do jornal La Mañana, chegava a mencionar o filme como um exemplo cabal da estratégia de coerção usada pelos "comunistas" para convencer o público não-comunista de que a democracia realmente não valia a pena.(ULIVE, 1967, p. 11)

Parece-nos que a motivação principal para que Martinez Carril desferisse suas críticas iniciais a Elecciones havia sido o entendimento de que, naquele momento histórico, a defesa da democracia uruguaia (ainda que imperfeita) deveria acontecer a todo custo, face $o$ possível crescimento do autoritarismo. Ele demonstra temer que os problemas apresentados

21 Ulive (1967, p. 11). Outras críticas ao filme assinadas por figuras de renome emergiramem meio a essa polêmica, como informa Mario Handler: "Benedetti escribió una crítica sensacional, quefigura en el libro El país de la cola de paja. Hace poco me llegó el maravilloso libro de Ulive, Cincuenta años de la vidade un artista, donde agrega una crítica que yo no conocía, la de Gerardo Gatti." (CONCARI, 2012, p. 52).

22 “Se agotan las entradas. X Festival de Marcha”. Marcha, Montevidéu, núm. 1357, 16 jun. 1967, p. 25. Sua exibição comercial, após o festival, foi possível pelo fato de Walter Achugar, colaborado de Marcha e próximo aos realizadores, ser o programador do Cine Renacimiento, sala onde o documentário foi projetado como complemento do filme El romance de Aniceto y la Francisca (Leonardo Favio, 1965), produzido pelo próprio Achugar (CONCARI, 2012, p. 55). 23 Crítico de cinema respeitado no meio uruguaio, frequentador assíduo não só das páginas de Marcha como também de outros periódicos. Segundo Ulive (1967, p. 11), a polêmica começou com o artigo "Al Borde del escándalo", de Manuel Martinez Carril, no jornal La Mañana que contava sobre o projeto do filme, mas fundamentava seus comentários em passagens inexistentes e informações equivocadas. 
no filme pudessem ser usados como exemplos da "falência" do regime democrático no Uruguai, alimentando posições conservadoras. Já a motivação de seus colegas de imprensa ao detratarem a mesma obra parece ter sido menos a defesa da democracia e mais a reação contra o crescimento da "subversão", visível, segundo eles, na ousadia demonstrada por aqueles cineastas "comunistas", antipatriotas, a detratarem seu próprio país.

Diante da saraivada de acusações, Marcha deu grande espaço para que Ugo Ulive se defendesse das críticas agressivas anti-comunistas e das primeiras observações do próprio Martinez Carril. Quanto a esse renomado crítico, que surpreendera negativamente os realizadores, Ulive acusou-o de ter escrito sobre o que não havia visto, ao que o crítico respondeu com a curiosa alegação de que repórteres policiais também escreviam sobre crimes sem tê-los visto, valendo-se de informações confiáveis. (ULIVE, 1967, p. 11). Ulive, além de listar as "calúnias" presentes nas resenhas, argumentou que ele e Handler pretenderam construir não uma sátira irresponsável e sim uma crítica densa, distanciada.

Durante o mês de fevereiro, os rumos tomados pela polêmica (que assumiu contornos politicamente conservadores nos discursos dos articulistas incomodados com o documentário) fez com que Martinez Carril, no mesmo jornal La Mañana onde havia publicado uma resenha em tom de reprovação à obra, mudasse o teor de seus comentários, provavelmente ciente do perigo daquelas avaliações para o destino do filme, ou algo culpado uma vez que muitas delas haviam sido embasadas por informações equivocadas que ele próprio havia publicado. Martínez Carril, face o acirramento das posições, procurou contemporizar, lembrando que os dois cineastas mereciam consideração pois já tinham, cada qual, produções premiadas no país (os filmes Como el Uruguay no hay, 1960, de Ugo Ulive, e Carlos, cine-retrato de un caminante, 1965, de Mario Handler). (ULIVE, 1967, p. 11).

O principal aspecto da polêmica que nos interessa frisar é justamente essa delicada questão da defesa da democracia como estopim para polarizações ideológicas de um lado e de outro, e o espaço que Marcha propositalmente confere a esse debate. Cabe notar que a defesa da democracia sempre foi uma bandeira empunhada por esse semanário, e facilmente identificada em seus editoriais nos anos 1960. Nesse momento, no entanto, o jornal, paralelamente, concedia gradativo espaço para obras e propostas revolucionárias, incluindo um sutil apoio a vozes que defendiam a luta armada, tanto da parte de intelectuais como de organizações políticas emergentes ${ }^{24}$. Essa tensa oscilação ideológica entre defesa da democracia e esperança na revolução perpassa as críticas voltadas ao cinema, às outras linguagens, e estará latente nas ações culturais empreendidas pelo jornal, como veremos mais adiante.

24 Como exemplo desse apoio podemos citar o fato de que foi organizado no Salón de Marcha (sededo jornal) o "Acto del Coordinador Juvenil Unitario Antiimperialista" em 20 de janeiro de 1967. Esse ato, em solidariedade aos povos que lutavam por sua libertação e contra o imperialismo norte-americano, contou com representantes de várias organizações de esquerda: MRO (Movimiento Revolucionario Oriental), MIR (Movimiento de Izquierda Revolucionaria), FAU (Federación Anarquista Uruguaya), Juventud Socialista. "Acto del Coordinador Juvenil Unitario Antiimperialista", Marcha, Montevidéu, n. 1338, 20 jan. 1967, p. 3. 
De toda forma, também não se pode perder de vista que a polêmica em torno de Elecciones expõe, de um lado, uma instituição muito cara à direção de Marcha, a Universidade de la República, a principal universidade do país de onde provinha parte substancial de seu público leitor e de sua equipe fixa de colaboradores. De outro lado, expõe o Sodre, organismo do Ministério da Cultura que detinha praticamente o controle total sobre o campo cultural, e que já estava na mira da direção do jornal há um certo tempo, em razão dos discutíveis critérios que permeavam sua política cultural, ainda que o periódico prezasse a participação e o mecenato exercido pelo Estado na cena cultural nacional. Vejamos as implicações dessa dupla exposição.

\section{Desdobramentos institucionais: Universidad de la República e Sodre}

Como vimos nos comentários críticos sobre o filme, acusava-se a Universidade de ter sido cúmplice de um projeto "subversivo". Essas opiniões, além do anticomunismo explícito, alimentaram as tensões internas entre o Instituto no qual Handler trabalhava e que viabilizou o filme, o já mencionado ICUR (Instituto de Cinematografia de la Universidad de la República) e a reitoria da mesma Universidade de la República (UdelaR) que, desde a realização de Carlos, vinha acatando com certa relutância os projetos de Handler (CONCARI, 2012, p. 45). Diante das acusações de "conivência", o Consejo Central da Universidade tenta, assim, preservar a duras penas sua "reputação" solicitando que os cineastas inserissem um aviso no início do documentário de que as opiniões ali expressas eram exclusivamente dos diretores. $^{25}$

Cabe aclarar que a Universidade, naquele momento, vivia um processo intenso de discussão de uma ampla reforma. Essas discussões, que vinham ocorrendo desde o início de janeiro $^{26}$, culminariam no Seminário de Estructura Universitária, em maio de 1967. Coordenado pelo brasileiro Darcy Ribeiro, que se encontrava exilado no país desde 1964 e assumira a Cátedra de Antropologia na UdelaR, o Seminário colocou em cheque a estrutura administrativa e o modo como os cursos se organizavam, naquele momento. (LIJSTENSTEIN, 1967, p. 6, 18). Por meio de trinta sessões com cerca de 40 participantes nas

25 Ulive (1967, p. 11). Nesse contexto de ampla polêmica, a própria Universidade hesitou em associar seu nome ao dos realizadores, chegando a reter a película, segundo a pesquisadora Cecilia Lacruz, para decidir sob quais condições institucionais esta seria exibida. Depois de Elecciones, Mario Handler foi suspenso do Instituto Cinematográfico de la Universidad de La República (ICUR) (LACRUZ, 2016, p. 316-317). Sobre a história do ICUR e as tensões políticas que o envolveram, ver: (WSCHEBOR, 2013).

26 Em abril há o anúncio da realização de uma assembleia, que tinha como "ordem do dia" a defesa da autonomia universitária. “Universidad dela República. Asamblea General de Claustro”. Marcha, Montevidéu, n. 1349, 21 abr. 1967, p. 18. 
mesas, entre professores e alunos egressos, discutiu-se um "modelo de universidade utópica", com mais autonomia administrativa, ênfase em cursos de extensão, estreitamente de relações com a educação básica, a sociedade, dentre outros pontos que procuravam rever sua hierarquia interna e a relação com o governo.

Devido aos limites desse artigo, não aprofundaremos esse tema: nosso interesse é demostrar que as tensões entre governo e Universidade se acirram nesse período, e persistem até o momento do golpe. Marcha, além de fornecer vários indícios desse clima de desconfiança mútua, nesse ano de 1967, toma partido da Universidade, ambiente do qual provinha um de seus mais ilustres colaboradores, Ángel Rama, crítico literário consagrado, além do escritor Mario Benedetti. A direção do jornal procura defender a autonomia da universidade e sua expertise como instituição cientifica. No artigo "Una creación infeliz", publicado em junho, por exemplo, o jornal criticou o Ministro da Cultura (Luis Hierro Gambardella, até então elogiado em diversos outros artigos) por ter criado, por iniciativa própria e como um organismo diretamente vinculado a esse Ministério, o Instituto de Literatura Latinoamericana com objetivos vagos de fomentar pesquisas e intercâmbios, uma vez que esse organismo apenas duplicaria (e concorreria) com um ente similar existente na Universidade: o Centro Latinoamericano de Documentación. A ameaça de interferência nos assuntos universitários representada por esse organismo criado da noite para o dia era sugerida em algumas passagens e no seguinte alerta feito ao leitor: "Demasiadas gestiones silenciosas ha habido en el país, y la experiência es por cierto negativa. Esta no parece que vaya a constituir una excepción". ${ }^{27}$

Outro desdobramento significativo da polêmica que envolveu Elecciones foi sua recusa pela organização do VII Festival Internacional de Cine Documental y Experimental del Sodre. Tal negativa gerou protestos e uma carta escrita pelo próprio Martinez Carril, na condição de presidente da Asociación de Críticos Cinematograficos del Uruguay, criticando a censura prévia feita a esse filme e a Pozo Muerto (documentário venezuelano de Carlos Rebolledo, de 1966). Essa carta foi publicada em Marcha, em maio de 1967, expondo as "regras abusivas" do Festival, que feriam a liberdade de expressão, como a seguinte norma: "No se admitirán en el festival películas que efectuen propaganda de hechos, sistemas o teorias políticas o religiosas con fines proselitistas". ${ }^{28}$ A carta também sugeria que Elecciones não era tão subversivo assim pois havia recebido elogios do Ministro da Cultura. Vemos, portanto, que o desenrolar dos acontecimentos influi nas posições adotadas por Martinez Carril, que deixa de atacar o filme para adotar sua defesa, meses após seu primeiro artigo. O mesmo Martinez Carril assumiria, em 1969, sob o contexto repressivo que caracterizou o Pachecato, uma postura explícita de cobrança de que críticos e artistas não se eximissem do posicionamento político, face à perspectiva de luta que se anunciava. Nesse outro contexto político o crítico, em tom de profecia, anuncia que nenhuma ordem social é definitiva e que, cedo ou tarde, "se 
producirá un enfrentamento de la coletividade con los desjustes sociales. En esse momento, público, críticos y artistas habrán cambiado su signo". (MARTINEZ CARRIL, 1969, p. 77).

Em 1967, para além do filme, a crítica se estendia ao formato vigente do Festival del Sodre, que, em sua primeira edição, em 1956, havia demonstrado uma grande vocação internacionalista, com promessas de incentivo à produção latino-americana reunindo realizadores importantes como o documentarista escocês John Grierson, o cineasta brasileiro Nelson Pereira dos Santos e o boliviano Jorge Ruiz. Quase uma década depois, no entanto, o festival se mostrava muito menos progressista ou tolerante em relação às abordagens de caráter social e menos afável com o cinema nacional. É esse o tom impresso no artigo de José Wainer, que denuncia a rejeição de Elecciones: "La Directiva del Sodre [...] como signo de su sombria gestión, prohibió la proyección del film sin que ninguna otra instancia superior hubiera revocado su medida. Esto es más que abandonar al cine nacional a su suerte: esto simplemente es atentar contra él". (WAINER, 1967c, p. 25). Wainer, nesse artigo, omite o fato de que havia sim, cinema nacional no Festival do Sodre: o filme Yo, de Ferruccio Mussiteli (1966), de caráter intimista e, podemos supor, bem mais inofensivo politicamente que Elecciones. ${ }^{29}$

Como vemos, Marcha dá grande cobertura à defesa do filme, aproveitando para elogiar outros filmes eliminados e desancar vários dos selecionados pelo Sodre, demonstrando alguma condescendência apenas com as animações (WAINER, 1967b, p. 28). Além disso, endossa uma feroz campanha pela reforma do Sodre (MAÑE GARZÒN, 1967, p. 9; TORRES FIERRO, 1967a, p. 14), cobrando que essa abarcasse o organismo em sua totalidade, de sua política televisiva a seu Festival. Marcha condenava os critérios de seleção adotados pelo Sodre e sugeria haver uma nefasta intervenção estatal: "el procedimento de selecionar las películas por mediación oficial, sólo porque el Sodre es un ente estatal, es la forma más segura de eliminar las películas que más interesan...”. (WAINER, 1967c, p. 25).

O papel do Sodre, na opinião do crítico Danubio Torres Fierro, deveria o ser o de proteção à produção nacional, postura que cobra do Ministro da Cultura: "o el Sodre actua como ente piloto para establecer un nivel cultural superior y ganar la competición artística, o habrá que establecer normas legales que defiendan la cultura uruguaya". (TORRES FIERRO, 1967, p. 24). O debate sobre os contornos do Sodre se arrastaria por anos a fio, mas nesse momento, é interessante perceber como a recusa do filme desencadeia ataques a esse organismo e aos traços de autoritarismo que nele já se expressavam.

29 Esse filme de Mussiteli é considerado, pelo crítico de Marcha, insatisfatório em termos de rigor e elaboração. (WAINER, 1967d, p. 27). 


\section{Marcha e a redenção do filme}

As notícias sobre a repercussão do filme em Marcha, entre março e junho de 1967, são acompanhadas, a partir do mês de maio, da divulgação dos preparativos de seu próprio festival de cinema: o Festival de Marcha, realizado no dia 24 de junho ${ }^{30}$.A presença de Elecciones na programação é anunciada ao longo de semanas, antes do evento. Sua exibição, na lotada sala "Censa", segundo Hugo Alfaro (1967, p. 23), em Marcha, foi seguida de "clamorosa ovación".

Este Festival, apesar do nome e da intensa campanha publicitária realizada no jornal, resumiu-se a uma jornada - bastante concorrida em termos de público - de algumas horas de exibição, durante a madrugada, que contemplou curtas e trechos de filmes de denúncia social, portadores de um discurso político de esquerda. Vemos, portanto, com esse evento, como a direção do jornal se empenhou em criar um espaço onde Elecciones e outros filmes "rejeitados" ou proibidos pudessem ser vistos: atua, portanto, como promotora da obra tanto em suas páginas como na cena cultural montevideana. Este evento e a cobertura da polêmica, dando voz aos realizadores, se apresentarão, assim, como oportunidades de redenção do filme. Além disso, vemos como a polêmica em questão estimula uma atuação de Marcha mais intensa em termos de política cultural. Nesse sentido, Elecciones emerge e é difundido em um momento em que está se desenhando um circuito cultural de esquerda cada vez mais evidente, do qual participa. Defendemos, em nossa pesquisa, que a atuação de Marcha foi fundamental para o estabelecimento desse circuito e de uma hegemonia cultural de esquerda, nos anos 1960, cujos traços ainda se fazem notar na sociedade uruguaia atual.

Para além do que o filme provocou em termos de recepção (seja de crítica como de público), é interessante notar que, como documento histórico, ele pode ser analisado levando-se em conta os dilemas políticos de um momento no qual a tradição democrática uruguaia é colocada em cheque por diferentes tendências políticas. Além de ter ficado sob um fogo cruzado entre a esquerda e a direita, ambas alegando a inconveniência da crítica à democracia naquele momento, por razões muito distintas, a obra revela, com seu final aberto e a prevalência da ironia, a inquietação de uma geração que buscava saídas para a situação nacional de crise política e econômica, mas que ainda não estava convicta de quais seriam as mais adequadas ao caso uruguaio. $O$ filme, muito menos assertivo que aqueles que

30 Em números consecutivos de Marcha há intensa divulgação de seu Festival: "X Festival Cinematográfico de Marcha": n. 1352, 12 maio 1967, p. 26; "X Festival Cinematográfico de Marcha", n. 1353, 19 maio 1967, p. 24; "X Festival Cinematográfico de Marcha. Vietnan a la pantalla", n. 1354, 27 maio 1967, p. 25; "X Festival Cine matográfico de Marcha. Nordeste y Cinema Novo", n. 1355, 2 jun.1967, p. 25; “Hoy se ponen en venta las entradas para el X Festival Cinematográfico de Marcha”. n. 1356, 09/06/1967, p. 23; “Se agotan las entradas, X Festival de Marcha”, n. 1357, 16 jun. 1967, p. 25; "Mañana. X Festival de Marcha. Nunca esperamos adhesion semejante”, n. 1358, 23 jun. 1967, p. 24-25. 
seriam realizados logo depois pela Cinemateca del Tercer Mundo, interroga, questiona e dá margem à dúvida.

Talvez por isso, Elecciones tenha tido pouca repercussão internacional e Handler manifeste ainda hoje certo desapontamento por esse "fracasso", uma vez que nem nos redutos mais simpáticos à produção uruguaia e ao documentarismo combativo dos anos 1960 o filme teve razoável acolhida, caso de Cuba e do Festival de Leipzig, onde foi, inclusive, recusado. Handler explica esse "fracasso" pelo fato de haver muitos filmes marcantes em circulação naquele momento, como El Chacal de Nahueltoro ou La hora de los hornos. (CONCARI, 2012, p. 54) Podemos alegar, também, razões ideológicas uma vez que o filme não faz nenhum chamamento à revolução e trabalha na chave da ironia. Anos mais tarde, seu conteúdo pouco "revolucionário" também o levaria a certa condição marginal na história do cinema uruguaio, não sendo sequer alçado à categoria de filmes que precederam ou participaram dos prenúncios da Cinemateca del Tercer Mundo, criada em 1969 (diferentemente de Carlos, por exemplo, visto como um notável precursor dos filmes "de combate" mesmo sem fazer apelo revolucionário algum, mas dando protagonismo a um personagem vítima da exclusão promovida pelo sistema capitalista). Independentemente do lugar que posteriormente o filme assumiu (ou não assumiu) no panteão do documentarismo uruguaio e latino-americano, a polêmica que despertou, em 1967, nos parece material rico para a compreensão dos dilemas políticos vividos no Uruguai, e um documento histórico que permite perscrutar o acirramento do autoritarismo e a resistência cultural que antecedeu a ditadura nesse país e que foi, de forma resoluta, encampada pelo semanário Marcha.

\section{Referências}

ACHUGAR, Hugo; CAETANO, Gerardo (Org.). Identidad uruguaya: ¿mito, crisis o afirmación? 3. ed. Montevidéu: Trilce, 1993.

ALDRIGUI, Clara. La izquierda armada. Ideologia, ética e identidad en el MLN-Tupamaros. Montevidéu: Trilce, 2001.

ALFARO, Hugo. Después del Festival. Marcha, Montevidéu, n.1359, p. 23, 30 jun. 1967.

ALFARO, Hugo. Navegar es necesario. Quijano y el Semanario Marcha. Montevidéu: Ediciones de la Banda Oriental, 1984. 
BRECHA. Historia: la historia de Brecha. Disponível em: <http://brecha.com.uy/historia/>. Acesso em: 2 nov. 2015.

CAETANO, Gerardo; RILLA, José P. Breve historia de la dictadura (1973-1985). Montevidéu: Centro Latinoamericano de Economía Humana, Ediciones de la Banda Oriental, 1987.

CHASQUETTI, Daniel. El proceso constitucional en el Uruguay del siglo XX. In: NAHUM, Benjamín (Coord.). El Uruguay del siglo XX: la política. Montevidéu: Ediciones de la Banda Oriental, ICP, 2004. Tomo 2, p. 64-63.

CONCARI, Héctor. Mario Handler: retrato de un caminante. Montevidéu: Trilce, 2012.

DE ARMAS, Gustavo; GARCE, Adolfo. Uruguay y su conciencia crítica. Intelectuales y política en el siglo XX. Montevidéu: Trilce, 1997.

DEL VALLE DÁVILA, Ignacio. Cámaras en trance: el Nuevo Cine Latinomaericano, un proyecto cinematográfico subcontinental. Santiago de Chile: Editorial Cuarto Próprio, 2014.

ELLECIONES. Direção e roteiro de Ugo Ulive e Mário Handler, direção de Rodolfo Tálice. Montevidéu: Instituto de Cinematografía de la Universidad de la República (ICUR), 1967. 16min., p\&b, 36'.

FERREIRA, André Lopes. A unidade política das esquerdas no Uruguai: das primeiras experiências à Frente Ampla (1958-1973). 2011. Tese (Doutorado em História) - Universidade Estadual Paulista, Assis.

LACRUZ, Cecilia. La comezón por el intercambio. In: MESTMAN, Mariano (Coord.). Las rupturas del 68 en el cine de América Latina. Buenos Aires: Ed. Akal, 2016. p. 311-351.

LIJSTENSTEIN, Marcos. La Universidad en tela de juicio. Marcha, Montevidéu, n. 1358, p. 6-18, 1967.

MACHÍN, Horacio; MORAÑA, Mabel (Ed.). Marcha y América Latina. Pittsburgh: Biblioteca de América, 2003.

MAÑE GARZÒN, Pablo. Cultura: añelos de un ministro. Marcha, Montevidéu, n. 1345, p. 9, 17 mar. 1967.

MARCHESI, Aldo et al. (Org.). El presente de la dictadura: estudios y reflexiones a 30 años del Golpe de Estado en Uruguay. Montevidéu: Trilce, 2004.

MARKARIAN, Vania. El 68 urugua yo. El movimiento estudiantil entre molotovs y música beat. Buenos Aires: Universidad Nacional de Quilmes Editorial, 2012. 
MARTINEZ CARRIL, Manuel. Apuntes para una cultura cinematogrática. Nuevo Film, Montevidéu, n. 4, p. 77, seg. sem. 1969.

NÚÑEZ, Fabián Rodrigo Magioli. O que é Nuevo Cine Latinoamericano? O cinema moderno na América Latina segundo as revistas cinematográficas especializadas latino-americanas. 2009. Tese (Doutorado em Comunicação) - Universidade Federal Fluminense, Niterói, 2009.

PADRÓS, Enrique Serra. Como el Uruguay no hay...Terror de Estado e Segurança Nacional. Uruguai (1968-1985): do Pachecato à ditadura civil-militar. 2005. Tese (Doutorado em História) - Universidade Federal do Rio Grande do Sul, Porto Alegre.

PEIRANO BASSO, Luisa. Marcha de Montevideo y la formacion de la conciencia latinoamericana a traves de sus cadernos. Buenos Aires: J. Vergara, 2001.

PRADO, Maria Ligia. Desafios do historiador brasileiro face às utopias latino-americanas do século XX. In: SIMPÓSIO NACIONAL DE HISTÓRIA, 26., 2011, São Paulo. Anais... São Paulo: ANPUH. p. 1-12.

PUBLICACIONES periódicas del Uruguay. Disponível em: $<$ http://biblioteca.periodicas.edu.uy>. Acesso em: 30 out. 2015.

REIS, Mateus Fávaro. Políticas da leitura, leituras da política: uma história comparada sobre os debates político-culturais em Marcha e Ercilla (Uruguai e Chile, 1932-1974). 2012. Tese (Doutorado em História) - Universidade Federal de Minas Gerais, Belo Horizonte.

REMUNDINI, Isadora. Maioria Absoluta (L. Hirszman, 1964) e a opinião pública (A. Jabor, 1967): uma análise histórica do documentário político-social frente aos debates da esquerda no Brasil. 2015. Dissertação (Mestrado em História) - Universidade Federal de São Paulo, São Paulo.

REY TRISTÁN, Eduardo. A La vuelta de la esquina. La izquierda revolucionaria uruguaya 19551973. Montevideo: Fin de Siglo, 2006.

ROCCA, Pablo. Treinta y cinco años en Marcha. Crítica y Literatura en Marcha y en Uruguay (1939-1974). Montevideo: División Cultura, Intendencia de Montevideo, 1992.

SARATSOLA, Oswaldo. Función completa, por favor. Un siglo de cine en Montevideo. Montevideo: Trilce, 2005.

SOLARI, Aldo. Uruguay. Partidos políticos y sistema electoral. Montevideo: El Libro Libre, FUCCYT, 1988.

TORRES FIERRO, Danubio. Conflicto con el SODRE. Marcha, Montevideu, n. 1352, p. 14, 12 maio 1967a. 
TORRES FIERRO, Danubio. La precisión de las cifras. Marcha, Montevidéu, n. 1354, p. 24, 27 maio 1967b.

ULIVE, Ugo. Memorias de teatro y cine. Montevideo: Trilce, 2007.

ULIVE, Ulive. Elecciones: Ugo Ulive puntualiza. Marcha, Montevidéu, n. 1344, p. 11, 10 mar. 1967.

VILlAÇA, Mariana. O 'cine de combate' da Cinemateca del Tercer Mundo (1969-1973). In: MORETTIN, Eduardo; NAPOLITANO, Marcos; KORNIS, Monica. (Org.). História e documentário. Rio de Janeiro: Ed. FGV, 2012. p. 237-271.

WAINER, José. Festival de Viña del Mar. Una cepa generosa. Marcha, Montevidéu, n. 1345, p. 25, 17 mar. 1967a.

WAINER, José. Festival del Sodre. Animación Über Alles. Marcha, Montevidéu, n. 1352, p. 28, 12 maio $1967 b$.

WAINER, José. "Festival del Sodre. Final de Juego". Marcha, Montevidéu, n. 1354, p. 25, 27 maio 1967c.

WAINER, José. Festival del Sodre. Renovación Gráfica y Dramática. Marcha, Montevidéu, n. 1353, p. 27, 19 maio 1967 d.

WAINER, José. Persecución y asesinato del Cine Nacional. Marcha, Montevidéu, n. 1355, p. 25, 2 jun. 1967e.

WSCHEBOR, Isabel. Cine y Universidad en la crisis de la democracia 1960-1973. Revista Encuentros Uruguayos, Montevidéu, n. 1, p. 50-84, 2013.

Recebido em 04/11/2015

Aprovado em 24/01/2017 